\title{
LEPROSY IN KOREA
}

R. G. Cochrane, M.D., F.R.C.P., D.T.M. \& H.

Adviser in Leprosy to the Ministry of Health.

Technical Medical Adviser, American Leprosy Missions.

\section{PART I}

\section{INTRODUCTION}

The problem of leprosy in Korea, like so many other problems, is one of great complexity. The war resulted in the division of the country and the migration of large sections of the population from North to South. The consequent disruption of the whole economy of the country, has faced the United Nations Organisations with almost unsurmountable difficulties. Great credit has to be given to these organisations, and particularly to the U.S.A.; for this country has undertaken and largely financed the enormous work of reconstruction and rehabilitation. The Republic of Korea, led by her President, has shown great courage and moral fortitude.

It would be wishful thinking to assume that all is now well in Korea, for there are still a multitude of dangers which threaten her. This brave little country, however, has demonstrated a determination both in war and in the uneasy peace which followed, which augers well for the future. With the improvement in international relationships there is hope that reunion between North and South will not be long delayed, for Korea cannot revive fully while she is dismembered. My task is not to give an over-all picture of disease conditions in Korea, fascinating and important though it is, but to outline the present situation with regard to leprosy.

\section{History, Distribution and Pattern of Disease}

Leprosy has been known in Korea for a thousand years or more. The Professor of Medical History at the National University -Dr. Kim-states that the first mention of lepers was about I300 A.D. The popular conception of leprosy is one of the great difficulties in the way of organising an adequate preventive programme. The disease is considered primarily, so Dr. Kim states, a hereditary disease, but infectious within the family, e.g. husband and wife, and other family members. Other factors, such as unfavourable weather, carelessness regarding health, and eating of fish have also been mentioned. The disease has been described 
under varying types, such. as slight leprosy, severe leprosy, alopecia, crow leprosy and white leprosy. I have not been able to ascertain why the last name has been given; from the description it seems to be the very advanced reacting lepromatous type. Each of these forms has a separate Korean name. A most interesting piece of information which I gathered was that there are among the Korean people two conceptions of leprosy: the one (Mung-Doong) corresponding to our word "leper" with all its sense of ostracism and disgrace, and the other (Napyong) meaning the disease of leprosy which seemed to be accepted with less sense of shame. These ideas are extremely illuminating and could form the starting point of an educational programme, for one of the first steps in any leprosy campaign is to prevent "Napyong " from becoming "Mung-Doong." All educational efforts in regard to leprosy should emphasise the fact that leprosy is a disease and not a social stigma, an infection transmitted mostly by contact in young life and not a Divine curse.

It has been long known that the incidence of leprosy is much higher in Southem than in Northem Korea. Owing to the division of Korea little is known of the leprosy situation in the North. In South Korea the most heavily infected areas appear to be the four southernmost provinces of Cholla Namdo, Cholla Pukto, Kyongsong Namdo and Kyongsong Pukto. In the province in which Seoul is situated-Kyonggi-Do-leprosy appears to be mainly an imported disease from the more highly endemic areas. The estimated numbers of cases in these provinces are:-

Cholla Namdo ... 7,942. Of these 7,329 are said to be in Leprosaria

\begin{tabular}{|c|c|c|c|c|c|}
\hline \multirow[b]{2}{*}{ Cholla Pukto _.. } & \multirow[b]{2}{*}{3,570} & \multirow[b]{2}{*}{ do. } & & \multicolumn{2}{|c|}{ or village colonies. } \\
\hline & & & 1,469 & do. & do. \\
\hline Kyongsong Namdo & 5,000 & do. & 2,988 & do. & do. \\
\hline Kyongsong Pukto... & 12,000 & do. & 2,177 & do. & do. \\
\hline Totals & 28,512 & & 13,963 & & \\
\hline
\end{tabular}

The above figures are a very rough estimate, but the figures from other provinces are still less reliable. It is, however, a fundamental principle in leprosy control to deal with the areas of highest incidence first, and not be over-concerned with regard to the leper problems in other areas.

\section{INCIDENCE OF LEPROSY}

\section{(a) Total number of cases}

Let us now consider the incidence of leprosy in relation to the number of known cases and the estimated number of cases in 
the country. The total number of cases in leprosaria and villages throughout the country as on December, I953, was I7,I88. Dr. Y. S. Yun, M.D., Chief of the Chronic Diseases section of the Ministry of Health, gives the total number of registered cases as on July, I954, as 25,000, with an overall estimate for South Korea of 45,000 . The question will now be naturally asked how near to the true figure is this estimate? It is well known that estimates based on general data, and not on more detailed surveys, are usually far from correct. Muir stated many years ago that the census figures in relation to leprosy in India could be multiplied Io times, and by so doing one came to a figure which is now given as the approximate number of cases in India, namely one million to one and a half million.

The figures for Korea are of registered cases taken from official files. It would, however, appear to me to be unrealistic to take this figure of 25,000 and multiply by ro and state that this is the probable number of cases in South Korea. I believe, however, we would be nearer the truth if we were to take the figure given by Government at the end of 1953, namely I7,I'

this by Io; this would give us an estimated total number of cases of leprosy of $I 7 I, 880$. Is there any possible method by which to check such an estimate? Dr. Paul Crane, of the Presbyterian Mission at Chonju, has been regularly examining children of school age and estimates the incidence of leprosy as from IO-I2 per thousand children examined. This would give an overall incidence of about 200,000 in South Korea. I realise, because of the uneven distribution of leprosy in any country, the fallacy of trying to compute the total number of cases in the whole country from data such as this. On the other hand, a certain number of cases would be missed in a routine school examination, particularly the very early initial lesions which need a much more careful examination to discover than would be possible in a general routine check of children in schools. Further, special experience is required to recognise these lesions. Therefore, taking all these factors into account, I think the figure of I50,000 cases for South Korea may not be an over-estimate. This would mean that in a population of 29 million the overall incidence would be 5 per thousand (approximately). It is not possible to give a more accurate figure, but in any case there are far more persons with leprosy than had been formerly imagined.

(b) Number of infective cases

However, from the public health standpoint, it is the total number of infective cases (including those likely to become 
infective) that is of chief importance. It seems to be a general observation that the proportion of infective cases to non-infective cases in the lighter coloured races of the world, e.g. the Mongolian and Caucasian, is higher ( 25 to 70 per cent) than in the darker people, e.g. Indian and African (I5 to 25 per cent). It is difficult to give a reason for this general observation; it may be that pigment has a greater influence on tissue defence in leprosy than has been realised. If the lower figure of 25 per cent infectiveness is taken, this would. give 37,500 cases in South Korea. While susceptibility to infection may not be greater among the lighter coloured races than among the darker, there seems to be a tendency in the former to develop more frequently into the serious lepromatous type. One is also struck on visiting institutions in Japan and Korea with the relatively high number of patients with extensive and crippling deformity. This makes leprosy in Korea all the more important and worthy of priority as an endemic disease. In addition to the number of serious cases which are likely to develop there is probably an equal number who are liable to become grossly deformed if proper physiotherapeutic and orthopaedic measures are not adopted for their relief, and this also means a loss to society of considerable manpower.

Apart from this, other factors must be taken into account which serve to retard all efforts at setting in motion a programme which would ultimately result in the control of leprosy in Korea. These factors are common elsewhere, but more so in Korea, and are as follows:-(I) the fear of ostracism which exists in the public mind towards leprosy, and the life-long separation it causes in the majority of instances; (2) the fact that in Korea leprosy is a serious endemic disease tends to be suppressed as it is feared it might affect the position of the country in the community of nations, and hence it is not given the public health importance that it deserves. Muir many years ago suggested that leprosy was most likely to be prevalent, other conditions being equal, in a society which was passing from the more primitive aboriginal or nomadic stage to an organised community, but had not yet fully arrived; (3) the place of leprosy in the overall Public Health programme tends to be overlooked, and general and preventive measures left to the care of voluntary organisations.

The Korean Civil Assistance Command and the Ministry of Health of the Republic of Korea have shown a commendable desire for guidance in their approach to a problem which they accept as urgent. The time therefore was opportune for a general appraisal of leprosy in the country and the American Korean Foundation (a 
volunteer organisation which assists Korea educationally and culturally), with the enthusiastic support of the British and American Leprosy Missions, invited me to visit the country for this purpose.

It is impossible after a short visit of six weeks to delineate accurately the whole picture of leprosy in the country. I have tried to understand the disease in South Korea as a whole by studying its distribution in the areas of highest incidence. There appear to be two main patterns of leprosy incidence: (a) that of the village, (b) that of the house. By the former I mean one in which a whole village has a high incidence of leprosy, and the disease is uniformly distributed throughout the village, whereas other villages a very short distance away may have none. To illustrate this from Indian experience, Saidapet-a suburb of Madras-in some streets had an overall incidence of leprosy of II per cent among children and 8 per cent in adults. Yet in a village a short distance away the incidence was less than 3 per cent. This latter village belonged to a community which was originally referred to as outcastes, but Mahatma Gandhi renamed them Harijans or people of God. This latter village was economically worse off than the former area of high incidence, yet the number of cases of leprosy was considerably less. On the other hand the pattern of the epidemic may be what I have termed " the house pattern," that is, houses in the village may not be uniformly affected, but individual houses in many villages in the areas may have cases in them. The determining factor as to the pattern of the epidemic appears to be the social structure of the family, and the inter-relationship of each family within the village. From the Public Health standpoint it is important to ascertain which is the prevalent pattern of disease, for methods which will suit one pattem may fail if the other is predominant. My impression was that in South Korea leprosy is a house rather than a village disease. The evidence for this is twofold. Firstly, the family unit is not that of the joint family, as in an Indian village, where communities are closely interwoven and marriage is confined to within one caste. In South Korea the family unit consists of mother and father, and not infrequently the elder son with his wife, and perhaps the grandfather. Other close relatives, e.g. younger sons or daughters, leave the home and establish their own homes elsewhere. Further, to marry within the clan is not considered proper and the son or daughter has a wife or husband chosen from another clan. This means that the family unit is compact, and leprosy spreads chiefly within the family and not readily to other 
relations, for instance son or daughter, and even the eldest son tends to drift away from the parental home. Secondly, in several of the larger leprosy colonies patients were persuaded to reveal the names of the villages from which they came

in a gun (district) or sub-district numerous cases may be recorded, but never were several houses in an individual village found to be affected in the series of areas investigated.

In attempting the control of leprosy in Korea, therefore, these basic facts must be kept in mind. Leprosy in Korea will be difficult to control because it is held in great fear. It will be hard to ascertain the source or origin of individual cases, for any public, semi-public or government inquiry for cases among the contacts of those already isolated would be considered to bring disgrace on the family. Theoretically when the disease manifests itself in the house-pattern it should be easier to control, because by tracing every known case the majority of infected individuals would be found. But, to achieve success presupposes an education in leprosy and a freedom from fear which has not yet been achieved.

(To be continued.) 